\title{
O EMPREGO DO POLYPTOTON POR MANUEL DIAS DE OLIVEIRA
}

\section{THE USE OF POLYPTOTON BY MANUEL DIAS DE OLIVEIRA}

\author{
Eliel Almeida Soares \\ Universidade de São Paulo \\ eliel.soares@usp.br \\ Rubens Russomanno Ricciardi \\ Universidade de São Paulo \\ rubensricciardi@gmail.com
}

\section{Resumo}

Esse artigo tem como proposta apresentar alguns exemplos no uso do Polyptoton por Manuel Dias de Oliveira. Após a introdução, haverá uma breve contextualização sobre a disposição do discurso musical e das funções dessa figura. Posteriormente, por meio de uma metodologia fundamentada em análises retórico-musicais em conformidade com o texto, harmonia e ordenação do discurso musical, serão demonstrados os resultados alcançados por esse estudo.

Palavras-chave: Retórica; Polyptoton; Manuel Dias de Oliveira; Musica Colonial Brasileira; Análise Musical.

\section{Abstract}

This article aims to present some examples in the use of Polyptoton by Manuel Dias de Oliveira. After the introduction, there will be a brief contextualization about the disposition of the musical discourse and of this figure features. Afterwards, through a methodology based on rhetorical-musical analysis in accordance to the text, harmony and arrangement of the musical discourse, will be demonstrated the results achieved by this study.

Keywords: Rhetoric; Polyptoton; Manuel Dias de Oliveira; Brazilian Colonial Music; Musical Analysis. 


\section{Lista de Figuras}

Figura 1: Polyptoton no Confitemini das Matinas e Vésperas de Sábado Santo - comp. 13-16. $1-7$.

Figura 2: Polyptoton no Pater Mihi do Moteto dos Passos- comp.

Figura 3: Polyptoton no Pater Mihi do Moteto dos Passos-comp. 32-39. 9-15.

Figura 4: Polyptoton no $\bigcirc$ vos omnes do Moteto dos Passos-comp. 15-23.

Figura 5: Polyptoton no Bajulans do Moteto dos Passos- comp.

Figura 6: Polyptoton no Kyrie da Missa do Oitavo Tom - comp. 1-7.

Figura 7: Polyptoton no Kyrie da Missa do Oitavo Tom - comp. $21-27$.

Figura 8: Polyptoton no Moteto Domine Jesu - comp. 12-15.

\section{Introdução}

Com o advento da Antiguidade greco-romana, passando por diversos períodos da história, chegando à atualidade, a retórica mostra-se como um instrumento de aplicação e de pesquisa que integra diferentes áreas do conhecimento humano. Isto é, para melhor compreensão da retórica se faz necessário que o pesquisador conduza sua averiguação para maior detalhamento tanto dos contextos filosóficos, históricos, hermenêuticos, políticos, sociais, estéticos e da arte. Nesse sentido, conforme Alexandre Júnior, que fez a introdução do livro Retórica de Aristóteles, o saber propiciado pela retórica é inspirado em outros saberes, os quais estabelecem uma inter-relação reciproca entre eles: 
A retórica é um conhecimento no sentido pleno da palavra, na medida em que se afirmou como arte de pensar e arte de comunicar o pensamento. E, como tal, pode se multiplicar em interdisciplinar e transdisciplinar, ela está presente no direito, na filosofia, na oratória, na dialética, na literatura, na hermenêutica, na crítica literária, na ciência e nas artes de modo geral (Manuel Alexandre Júnior, In: ARISTÓTELES, 2005, p. 10).

Certamente, tais propriedades revelam-se fundamentais para a constituição de um discurso, pelo fato de "a retórica ser uma ferramenta estimuladora que assessora o orador no convencimento do auditório positivamente à sua tese", como destaca Elisa Guimarães (CUIMARÃES, 2004, p. 145). Logo, como enfatiza Soares, havia "uma ordenação de mecanismos que privilegiasse uma escolha diligente de diversos artifícios semânticos, alegóricos, metafóricos e de figuras retóricas, instaurando, desse modo, conceitos tangíveis e eficazes" (SOARES, 2014, p. 1; SOARES, 2017, p. 49). Destarte, esses princípios eram balizados em pensadores e teóricos como Aristóteles (384-322 a. C.), Cícero (106-43 a.C.), Quintiliano (ca. 35-ca. 96), Santo Agostinho (354-430), Santo Isidoro de Sevilha (570-636), para citar alguns, os quais influenciaram numerosos tratadistas retórico-musicais, além de grande parte dos compositores do final do século XVI e do começo do século XIX.

Somado a isso, esses preceitos são examinais em Manuel Dias de Oliveira (? - 1734/5 - Vila de São José, 1813), mediante o emprego na organização de determinadas obras, de elementos retóricos com o propósito de esclarecer as seções e as disposições do discurso musical. Por exemplo, Maurício Dottori realça que, Manuel Dias de Oliveira "usa os elementos retóricos, seja mediante as frequentes cadências ou pela linha do contraponto somado a ênfase dos afetos" (DOTTORI, 1992, p. 53). Também, segundo Dottori apud Ricciardi (2000) Dias de Oliveira emprega artifícios semelhantes em sua obra $O$ vos omnes, do Moteto dos Passos, onde o mesmo tipo de baixo cromático utilizado para descrever o afeto de tristeza e desespero, como no Lamento de Cassandra, da ópera Didone (1641), de Francesco Cavalli (1602-1676), por meio da figura retórica da Pathopoeia (pathos, que em grego significa toda forma de sentimento humano, paixão, carinho, poeia, apresentação, expressão) (DOTTORI, 1992, apud, RICCIARDI, 2000, p. 28). Finalmente, Soares (2019), destaca que Manuel Dias de Oliveira usa a Anaphora, figura retórica melódica, no Pater Mihi do Moteto dos Passos, para 
enfatizar nos compassos 15 a 20, a repetição continuada apenas do baixo, em que a expressão, transeat a me (afaste de mim), descreve o afeto de angústia e languidez expressadas por Cristo, antes de sua crucificação. De sorte, que, ainda na mesma obra, observa-se que a Synaeresis, figura retórica de dissonância e deslocamento, em que duas notas são colocadas numa sílaba ou vice-versa, reitera esse sentimento, trabalhado por Dias de Oliveira, seja nos diálogos entre as funções harmônicas da Tônica e Dominante, seja nas vozes (SOARES, 2019, p. 11).

Apoiados nessas asserções, o presente trabalho faz uma verificação desses processos em Manuel Dias de Oliveira, observando o uso da figura retórica de repetição melódica Polyptoton, tendo por metodologia, análises retórico-musicais relacionadas ao texto sacro, harmonia e distribuição do discurso musical, as quais serão apresentadas como resultado de pesquisa, em alguns exemplos.

\section{As cinco fases retóricas: organização do discurso musical}

Como ressaltado em diversos livros, teses, dissertações, artigos, capítulos de livros, trabalhos e textos relacionados a esse tema de pesquisa, é necessário que antes do exame dos exemplos das análises efetuadas, haja uma breve consideração sobre a disposição do discurso musical, além da forma de como o compositor organiza cada mecanismo retórico.

Primeiramente, a arte da eloquência é uma ferramenta que estimula e auxilia o orador para que suas argumentações possam convencer 0 público. Não obstante, por intermédio de uma organização diligente de diversos elementos retóricos, anteriormente listados na introdução, além do embasamento nos mestres da retórica da Antiguidade e ldade Média, vários teóricos, compositores, pesquisadores e autores da disciplina, na transição da Renascença para o Barroco e começo do Classicismo, desenvolveram um modelo de sistematização e teorização, objetivado em atrair, persuadir e mover os afetos do ouvinte, conhecido como Musica Poetica (Ver: SOARES, 2012, p. 47-48; SOARES, 2017, p. 115). 
Dentre os diversos tratadistas retórico-musicais, pode ser ressaltado que Johann Mattheson (1681-1764) em sua obra, O mestre de capela perfeito (Der Vollkommene Capellmeister) (1739), apresenta um parâmetro composicional fundamentado nos mesmos preceitos retóricos, com resultados eficazes e semelhantes aos da arte da oratória. Os quais podem ser verificados através da descrição de George Buelow, desse modo:

- Inventio - fase inicial do discurso, descoberta das ideias e dos argumentos que sustentarão a tese do orador, invenção e elaboração das ideias musicais;

- Dispositio - ordenamento e distribuição das ideias e argumentos encontrados na Inventio;

- Elocutio - refere-se ao estilo. Aqui são constituídos os procedimentos de cada ideia, para o desenvolvimento de cada item e da sua ornamentação, igualmente denominada por Decoratio ou Elaboratio;

- Memoria - empregam-se diferentes modos e processos para memorizar o discurso; também, é a forma de operação de cada uma das fases retóricas;

- Pronuntiatio - última fase retórica, onde é proferido o discurso. Também denominada, como Actio ou "ação" (atuação) diante do publico, ou seja, sua performance (BUELOW, 200 l, p. 261).

Em relação à Dispositio, Buelow acentua que alguns autores como Gallus Dressler (1533-1589), efetuaram uma versão dessa fase de modo simplificado, em três partes (Exordium, Medium e Finis). Entretanto, analogamente aos cânones clássicos, Mattheson as distribui em seis partes, dessa maneira: 
- Exordium - início do discurso;

- Narratio - declaração ou narração daquilo que acontece;

- Propositio ou Divisio - exemplificação da tese fundamental, aqui o conteúdo e objetivo do discurso musical se dão de forma sucinta;

- Confutatio - refutação aos argumentos expostos. Nessa parte se localizam as ideias contrárias;

- Confirmatio - confirmação da tese inicial;

- Peroratio - final do discurso. (BUELOW, 2001, p. 262).

\section{Polyptoton: suas funções e características}

orador ao elaborar seu discurso, emprega diversos recursos retóricos para obter êxito a sua propositura. Num abundante repertório de figuras retóricas, seleciona a que mais se adequa ao momento contextual do enunciado. Desse modo, para realçar seus argumentos, dentre as diversas opções, opta pelo Polyptoton, que é um recurso retórico de repetição integrada das palavras (LAUSBERG, 2004, p. 164).

Diferentemente de outras figuras retóricas de repetição melódica, Anaphora e Epizeuxis ou figuras retóricas de interrupção e silêncio, Aposiopesis e Pausa, no Polyptoton não são localizadas muitas definições sobre suas características e funções. Assim, embasados em autores como Bartel (1997), López Cano (2000) e Buelow (200 l), exporemos algumas definições de tratadistas de retórica musical.

Musicalmente, conforme Dietrich Bartel e George Buelow, o Polyptoton "é a repetição de uma passagem melódica em diferentes alturas" (BARTEL, 1997, p. 369; BUELOW, 2001, p. 264). Semelhantemente, Rubén López Cano, afirma que o Polyptoton, "é uma repetição de um mesmo fragmento musical, numa outra voz" (LÓPEZ CANO, 2000, p. 
138, tradução nossa)'. Para Johannes Susenbrotus (1484-1542), o Polyptoton é nominado pelos poetas por sua variedade de terminações em diferentes casos. Ele ocorre numa repetição de uma expressão ou palavras, "This figure is called Polyptoton by poets and is distinguished through a variety of different case endings. According to Mancinellus, it is marked by the repetition of a word in various cases" (BARTEL, 1997, p. 369). Mauritius Johann Vogt (1669-1730) realça que o Polyptoton acontece "Quando a passagem é repetida a diferentes alturas" (BARTEL, 1997, p. 369, tradução nossa) ${ }^{2}$. $\bigcirc$ mesmo autor, semelhantemente destaca que a referida figura é "a repetição de uma ideia melódica num registro diferente ou numa voz/parte diferente” (BUELOW, 200 1, p. 264, tradução nossa) ${ }^{3}$. Por outro lado, Johann Mattheson descreve essa figura retórica do seguinte modo:

A Epanalepsis, Epistrophe, Anadiplosis, Paronomasia, Polyptoton, Antanaclasis Place, etc. São figuras dispostas de forma tão natural que quase parecem que foram tomadas, pelos oradores gregos, diferamente da arte da composição musical; por elas serem repetições de vozes, repetições de palavras, que são aplicadas na música de várias maneiras diferentes (BARTEL, 1997, p. 183; 258; 261; 262; 351; 369, passim, tradução nossa) ${ }^{4}$.

Em sintese, pode-se observar que a referida figura não serve somente para repetir expressões e palavras em diferentes vozes, mas, sua utilização é relevante e necessária na ordenação do enunciado musical, assim como na valoração das reiterações e destaques das palavras, frases, notas e dinâmicas das mesmas. De igual forma, para realçar as funções harmônicas, progressões melódicas, bem como nas resoluções cadenciais. Estas contextualizadas e adequadas em cada parte do discurso pelo compositor, com finalidade de estabelecer relação entre afeto e figura, como verificado nos exemplos a seguir.

I Es la repetición de un mismo fragmento musical, en otra voz.

2 When a passage is repeated at various pitches.

3 The repetition of a melodic idea in a different register or different part.

4 The Epanalepsis, Epistrophe, Anadiplosis, Paronomasia, Polyptoton, Antanaclasis Place, etc., assume such natural positions in music that it almost seems as if the Greek orators borrowed these figures from the art of musical composition. For they are purely repetitiones vocum, repetitions of words, which are applied to music in various different ways. 


\section{Exemplos de Polyptoton em algumas obras de Manuel Dias de Oliveira}

Na primeira figura, escolhemos um exemplo que foi examinado anteriormente pelo primeiro autor em seu doutorado. Entretanto, nesse trabalho, optamos por observar somente o elemento retórico do Polyptoton. A peça em questão, $\bigcirc$ Confitemini das Matinas e Vésperas de Sábado Santo têm seu texto fundamento em Salmos (Ps.117:12/118:1-2) $)^{5}$, cujo título faz referência à alegria dos justos no Senhor (SOARES, 2017, p. 264; SOARES, p. 2019, p. 9).

Notadamente, esse salmo é o término da seção associada à celebração pascal, introduzida no salmo 113. Como parte constituinte e último cântico do grupo (113-118), possivelmente foi o salmo proferido por Cristo nesse cerimonial com seus discípulos, "Ainda não lestes esta Escritura: A pedra que os construtores rejeitaram, essa veio a ser a principal pedra, angular; isto procede do Senhor, e é maravilhoso aos vossos olhos?" (Marcos 12:10-11 [36]; Salmos 117:22-23/118:2223, 1999 [ 1000 a.C.] ALMEIDA, 1999, p. 700).

No entanto, nessa passagem, o salmista conclama todos os povos a louvar e a glorificar o Senhor, por causa de seus atributos. Assim, nesse trecho examina-se o uso do Polyptoton na qual a mesma ideia musical é notada através da repetição nas diferentes vozes, enfatizando a expressão, in sceculum (século). De igual natureza, podese observar que esse recurso retórico de repetição é objetivado em salientar as progressões harmônicas das funções da Tônica, Dominante, Subdominante, Dominante Relativa (Paralela), Tônica Relativa (Paralela) e Subdominante Relativa (Paralela).

5 Salmo s 1 17:1-2 seriam o número e versículo na Bíblia Católica; já na Bíblia Protestante, o texto está escrito no número 118 versículos 1 e 2. 


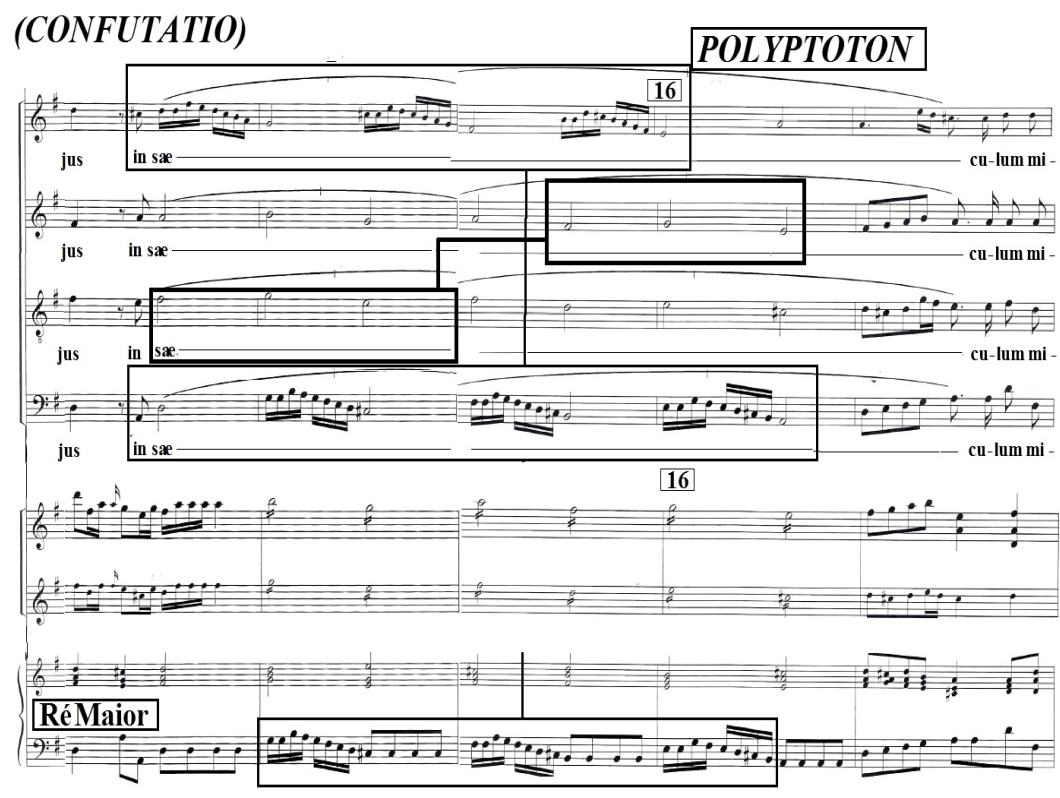

Figura 1: Polyptoton no Confitemini das Matinas e Vésperas de Sábado Santo - comp. 13- 16 Edição-Maurício Dottori (OLIVEIRA, 2000, 129-130).

- Moteto dos Passos descreve o padecer pelo qual passou Jesus antes, durante e depois de sua crucificação. Todo esse sofrimento é relatado por meio de seus passos desde sua indagação a Deus no Cetsêmanib, pedindo para que passasse Dele aquele cálice, entretanto, fosse realizada a vontade de seu Pai, até o momento de sua humilhação ao longo do caminho percorrido. Manuel Dias de Oliveira dispõe esse moteto em sete partes, sendo analisada, neste artigo, a primeira. $\bigcirc$ texto dessa parte pode ser localizado em três dos quatro evangelhos bíblicos: Mateus 26:39, Marcos 14:36 e Lucas 22: 42.

Na segunda figura, nota-se a repetição literal, tanto das notas quanto das palavras, ou seja, em alturas diferentes nos compassos 1 a 7. Entretanto, abre-se uma questão hermenêutica e de significação musical, pois a mesma passagem pode ser classificada, interpretada e configurada por alguns tratadistas como uma Analepsis, que é definida

6 É um jardim localizado ao pé do Monte das Oliveiras, em Jerusalém. Nesse lugar, a agonia de Jesus foi tão grande que seu suor transformara-se em gotas de sangue. 
por Joachim Burmeister ( 1564 - 1629), “como uma repetição ou duplicação de um Noema (passagem homofônica numa textura contrapontística e polifônica) e, portanto, é um ornamento relacionado a ele" (BARTEL, 1997,184). Em sua Musica Poetica, Burmeister (1993[1606]) destaca que a Analepsis, uma figura de repetição literal acontece numa seção homofônica. $\bigcirc$ tratadista continua sua dissertação, afirmando que 0 Exordium é, normalmente, ornamentado pela fuga, de maneira que os ouvidos e a mente do ouvinte são submetidos atenciosamente à melodia. Igualmente, o início do discurso pode-se estender até o ponto em que o sujeito de uma fuga, por exemplo, termina com a introdução de uma cadência ou passagem harmônica semelhante. No entanto, algumas vezes, pode ocorrer um Noema no Exordium (BURMEISTER, 1993[1606], p. 203).

Todavia, além da interpretação analítica efetuada por Eliel Almeida Soares em seu doutorado (Soares, 2017, p. 279), do uso entre os compassos 1 e 7 da Analepsis, verifica-se agora nesse trabalho, que há repetições tanto das palavras, motivos e em diferentes vozes, possibilitando dessa forma, a localização de um Polyptoton. Enfim, observou-se o diálogo estabelecido entre as vozes e as funções da Tônica e Dominante, na reiteração da frase: Pater mihi, si possibile est (Meu Pai, se for possivel), onde Dias de Oliveira trabalha com esse recurso retórico para destacar o afeto de extrema angústia e sofrimento, com resolução na Cadência Autêntica Perfeita. 


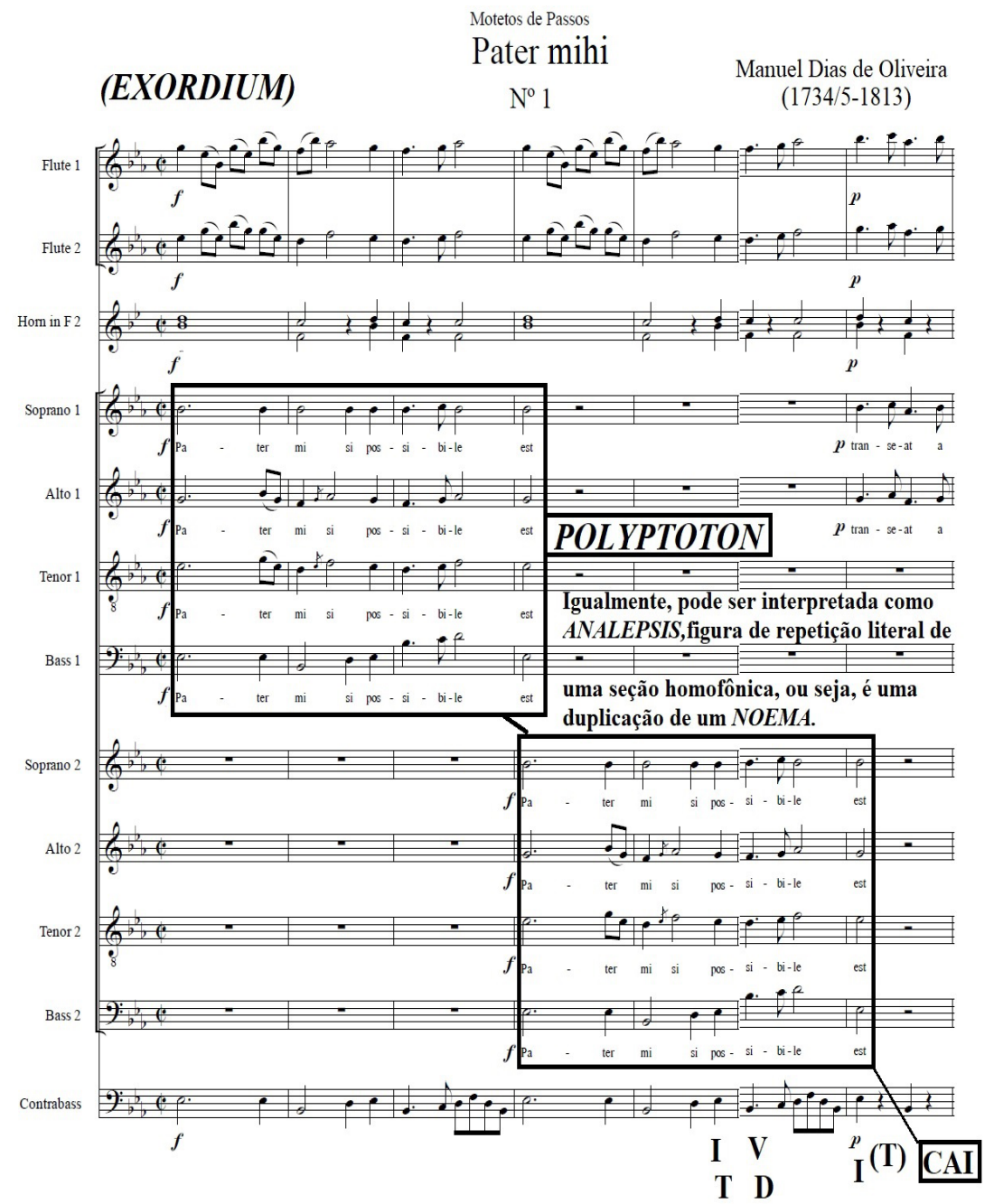

Figura 2: Polyptoton no Pater Mihi do Moteto dos Passos de Manuel Dias de Oliveiracomp. 1-7. Restauração- Maurício Dottori (OLIVEIRA, s/d, p. 1-2).

Para atrair a expectativa do ouvinte, o compositor utiliza mecanismos retóricos de repetição harmônica e melódica como do Polyptoton, realçando a expressão: non sicut ego volo (não se faça como eu quero). É pertinente salientar, também, o retorno para a 
tonalidade inicial da peça em Mi bemol Maior no compasso 35, com terminação na Cadência Autêntica Imperfeita.

\section{(CONFUTATIO)}

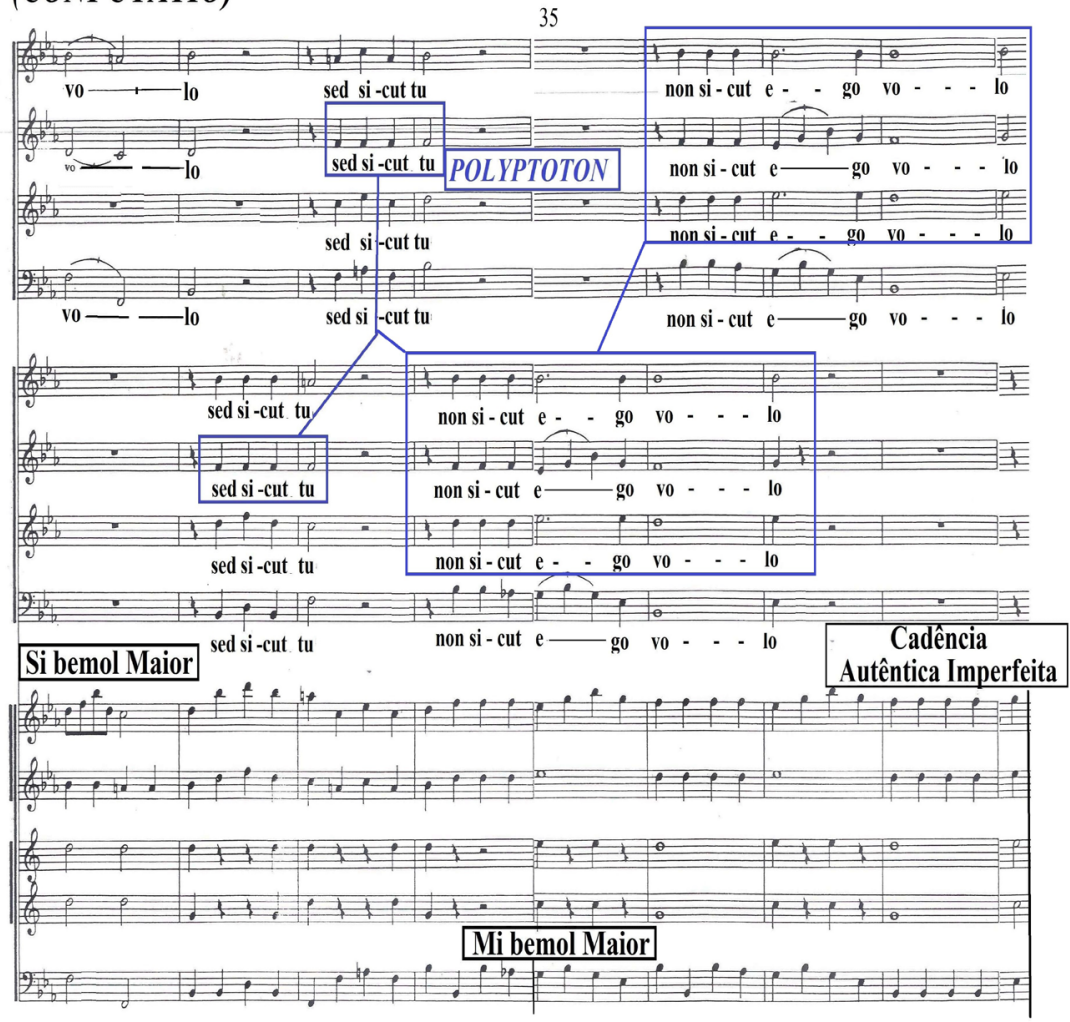

Figura 3: Polyptoton no Pater Mihi do Moteto dos Passos de Manuel Dias de Oliveiracomp. 32-39. Restauração- Maurício Dottori (OLIVEIRA, s/d, p. 9-11).

Vos Omnes do Moteto dos Passos, tem seu texto extraido do livro das Lamentações de Jeremias 1:12, 0 vos omnes, qui transitis per viam, attendite et videte, si est dolor similis sicut dolor meus (Não vos comove isto, todos vós que passais pelo caminho? Considerai e vede se há dor igual à minha, que veio sobre mim, com o que o Senhor me afligiu no dia do furor da sua ira). Nessa parte, verifica-se o Polyptoton 
usado para não só para ressaltar a repetição literal das notas, motivos e da expressão Attendite et vide (olhem e considerem), com resolução na Semicadência. Mas, também, para descrever o afeto de dor, angústia e solidão passados por Cristo carregando Sua cruz, por meio de movimentos lentos e reflexíveis, pelo caminho até o Cólgota.

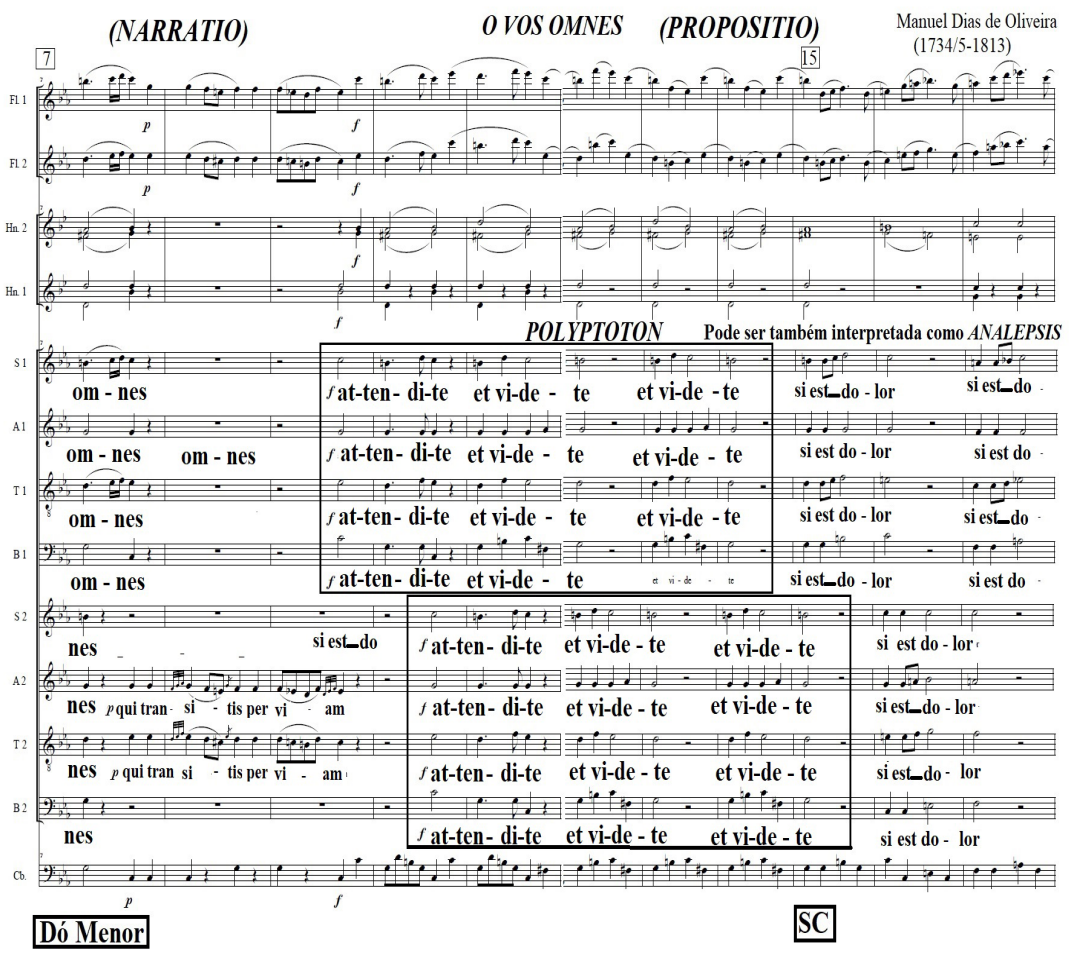

Figura 4: Polyptoton no $\bigcirc$ Vos Omnes do Moteto dos Passos de Manuel Dias de Oliveira-comp. 9-15. Edição de Rafael Sales Arantes (OLIVEIRA, 2017 , p. 28-29).

Parte constituinte do Moteto dos Passos, Bajulans tem seu texto baseado em João 19:17, no qual é narrado o sofrimento de Cristo, carregando sua cruz até o Gólgota. Nesse exemplo, examina-se que - Polyptoton é empregado para enfatizar esse momento, além das repetições das notas, das vozes e das palavras, Bajulans sibi crucem Jesus (Tomaram eles, pois, a Jesus; e Ele próprio, carregando a Sua cruz). 


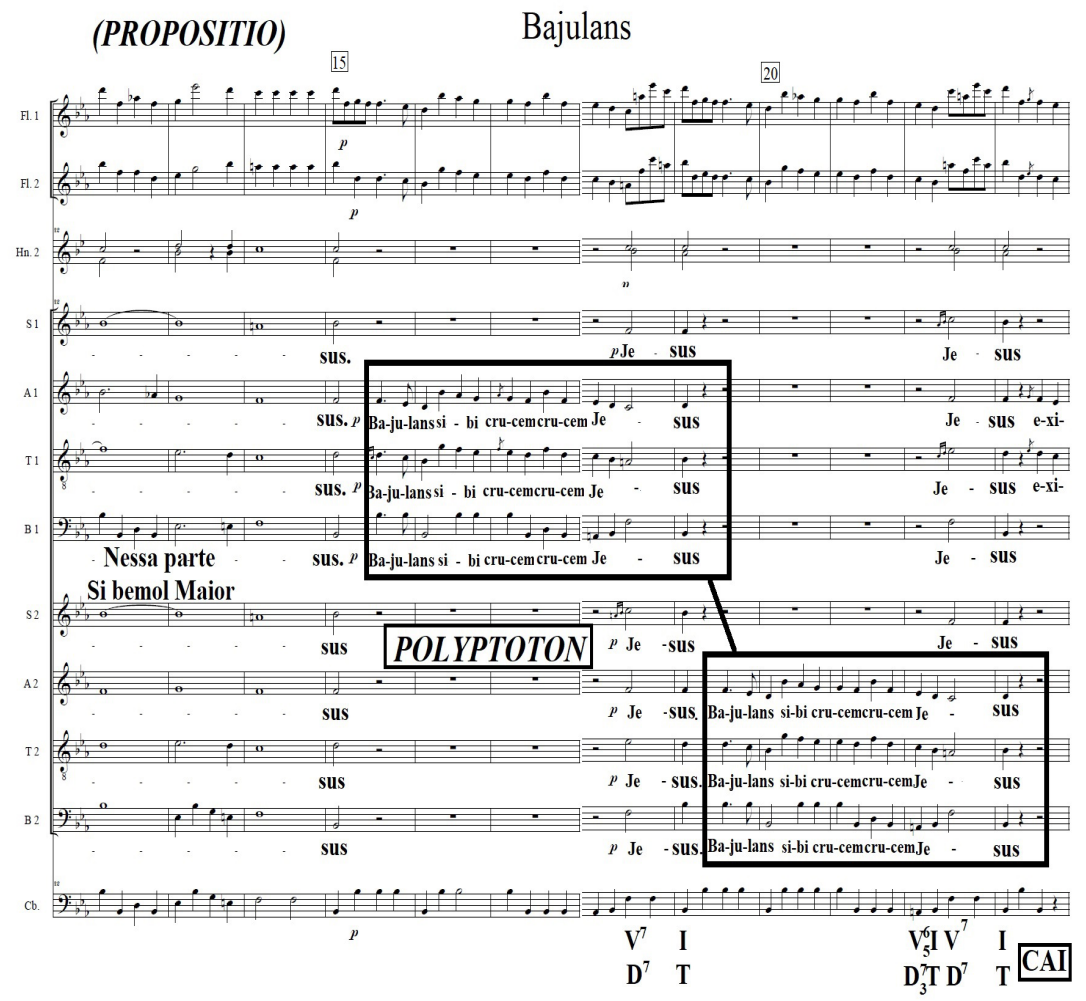

Figura 5: Polyptoton no Bajulans do Moteto dos Passos de Manuel Dias de Oliveiracomp. 15-23. Edição de Rafael Sales Arantes (OLIVEIRA, 2017, p. 28-29).

A Missa de oitavo tom de Manuel Dias de Oliveira foi destinada aos Domingos da Quaresma (incluindo o Domingo de Ramos). De acordo com Paulo Castagna:

É importante observar que, embora o oitavo tom (hipomixolídio) esteja indicado na fonte A, predomina no baixo dessa composição o primeiro tom mollis (dórico com o sexto grau menor), que também pode ser interpretado como décimo tom (eólio), tal como ocorre nas frases em cantochão. $\bigcirc$ sétimo tom (mixolídio) - e não o oitavo 
- está apenas sugerido no Christe polifônico. De qualquer maneira, o título e a textura dessa Missa parecem refletir certo distanciamento $e$, consequentemente, uma visão particular da prática composicional do estilo antigo (barroco) (CASTACNA, 200 l, p. XIX, negrito nosso).

Desse modo, entre os compassos 1 e 7, da referida obra, evidenciase que o Polyptoton é aplicado para ressaltar tanto a expressão Kyrie eleison (Senhor tende piedade de nós), reiterada nas vozes da soprano e do tenor, como do afeto de humildade e devoção, das funções harmônicas da Tônica e Dominante, além da modulação de Mi Menor para Sol Maior.

\section{MISSA DE OITAVO TOM}

\section{Kyrie}

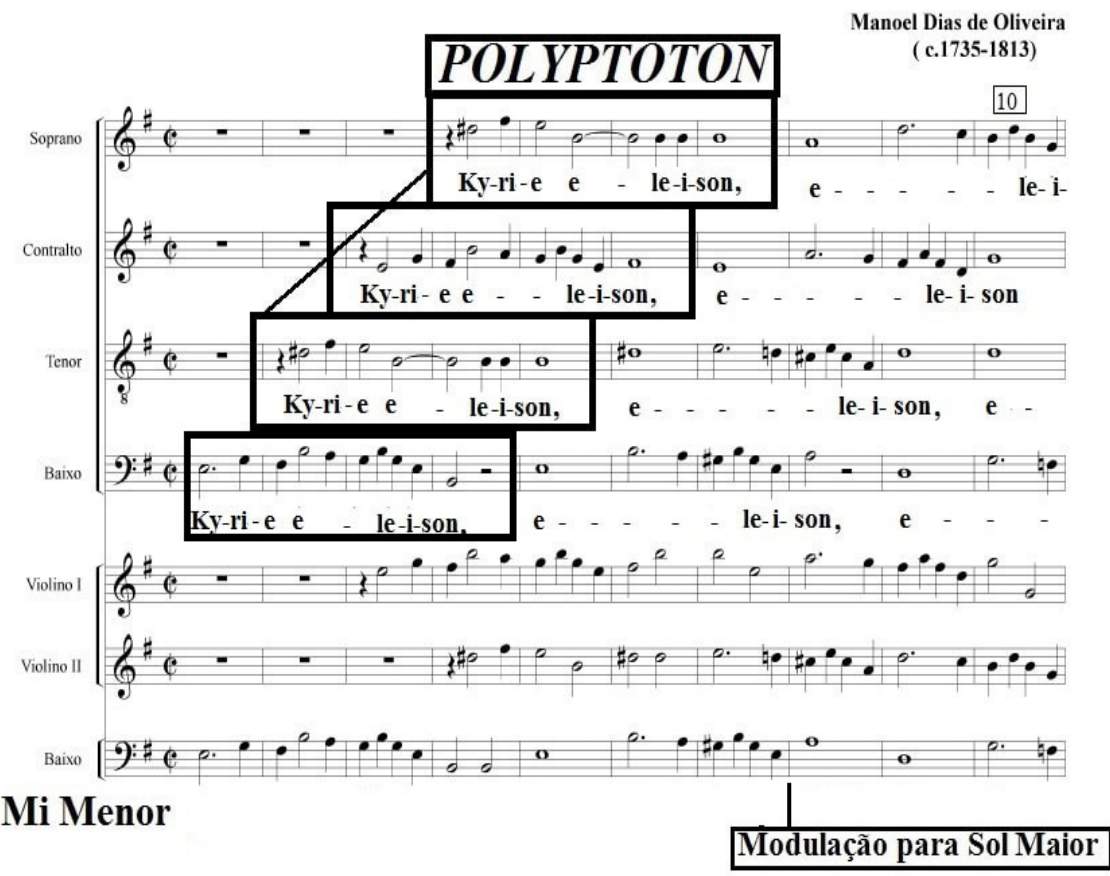

Figura 6: Polyptoton no Kyrie da Missa do Oitavo Tom - comp. 1-7. Edição e

Organização- Paulo Augusto Castagna (CASTACNA, 200 I, p. 1). 
Verifica-se nos compassos 21 a 27, da mesma obra, o mesmo procedimento e uso desse elemento retórico de repetição melódica, destacando os mesmos afetos, expressões, frases, melodia e funções harmônicas.

2

Missa de Oitavo Tom (Kyrie)

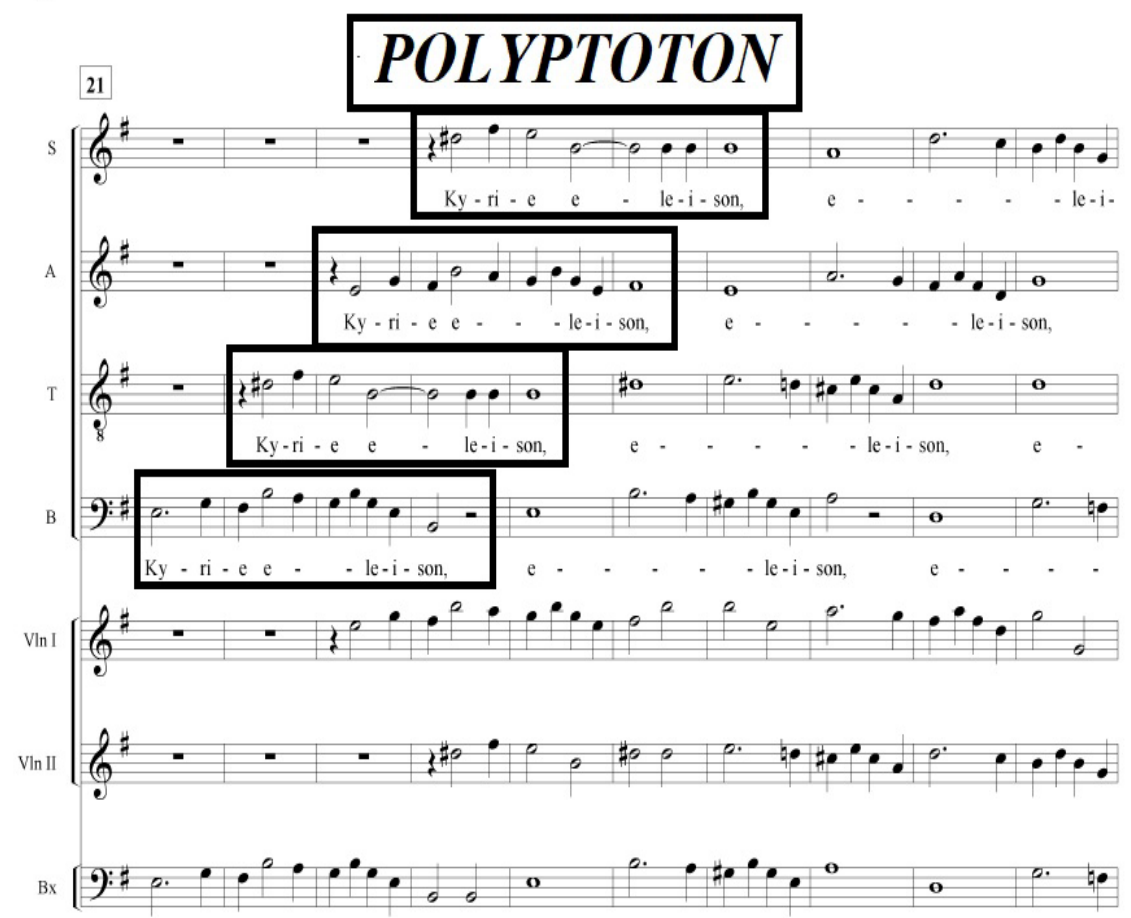

Figura 7: Polyptoton no Kyrie da Missa do Oitavo Tom - comp. 2 1-27. Edição e Organização- Paulo Augusto Castagna (CASTACNA, 2001, p. 2). 
Essa peça tem seu texto baseado nos Salmos (Ps. 79:3/80: 1), tendo por tema principal: A Salvação pelo Senhor. Nada obstante, observa-se à vontade e o propósito do autor desse salmo em buscar a presença do Senhor. Asafe, nessa passagem, enfatiza três coisas na sua súplica para conseguir proteção divina: o desejo, a procura e, por fim, o querer.

Na figura 8, examina-se o emprego do Polyptoton, que além de repetir as mesmas passagens musicais em diferentes vozes, valora a frase, Ostende mihi faciem tuam (Mostra-me a tua face) na tonalidade Si bemol Maior.

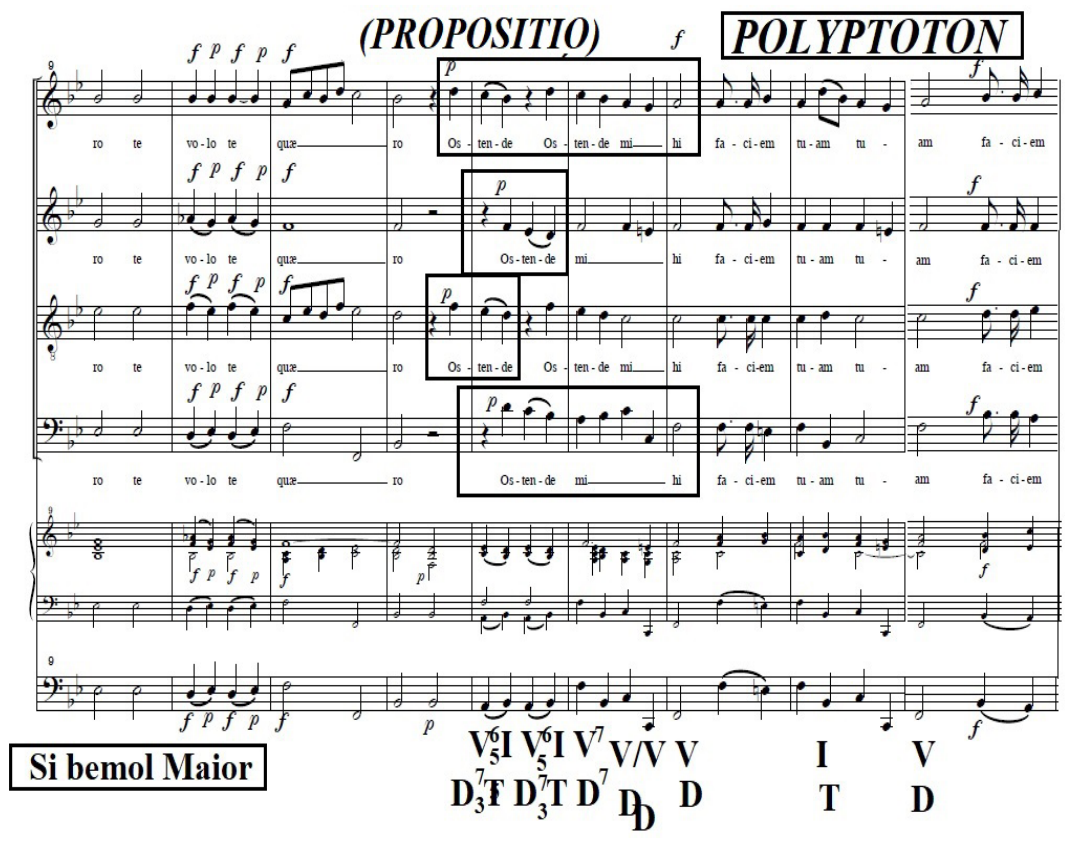

Figura 8: Polyptoton no - Domine Jesu - comp. 12-15. Edição: Rubens Russomano Ricciardi (RICCIARDI, 2017, p. 622). 


\section{Considerações Finais}

Muitos dos mestres da composição empregavam elementos retóricos em determinadas obras com a finalidade de despertar os afetos dos ouvintes, mediante da eloquência e persuasão. Certamente, para obterem um resultado eficaz, recursos como as figuras retóricas, tal como o Polyptoton, foram usadas pelos autores não só para reforçar a elaboração e disposição do discurso de suas peças, mas, de igual forma, para valorar a harmonia, as resoluções das cadências, o contraponto, as vozes, as melodias, repetições, na ênfase das palavras, nas frases. E, finalmente, nos afetos cuidadosamente trabalhados, o que se apresentava como artifício eficiente dentro de uma composição engenhosamente inventada $e$, inter-relacionada com outras partes formadoras de um arcabouço semântico, textual, motívico e instrumental.

Examinando esses exemplos nas obras de Manuel Dias de Oliveira, notou-se o uso do Polyptoton, disposto e ajustado em consonância as circunstâncias do discurso de cada peça. Por exemplo, no Confitemini das Matinas e Vésperas de Sábado Santo, ressaltando o afeto de júbilo e alegria. No Pater Mihi do Moteto dos Passos, para reiterar o sentimento de extrema tristeza e angústia, Pater mihi, si possibile est (Meu Pai, se for possivel). Também, na mesma obra, já em outra parte do discurso retórico, para reforçar o afeto de devoção e confiança de Cristo, mediante e expressão, non sicut ego volo (não se faça como eu quero). No $O$ Vos Omnes e em Bajulans do Moteto dos Passos, evidenciando e descrevendo o sofrimento de Cristo e seus passos, carregando à cruz. No Kyrie da Missa do Oitavo Tom, valorando a mudança da tonalidade Mi Menor para Sol Maior, bem como a repetição de todas as vozes da expressão Kyrie eleison (Senhor tende piedade de nós). Por fim, no Moteto Domine Jesu, dando ênfase ao afeto de submissão, devoção e confiança do fiel para com seu Senhor.

Mediante essas ponderações, enfatizamos os desafios de ordem hermenêutica em identificar e diferenciar gestuais das figuras retóricas numa categorização e universo comum a todos. Tal como observado, nos três exemplos, do Pater Mihi e $\bigcirc$ Vos Omnes do Moteto dos Passos, os quais podem ter duas possíveis aplicações de figuras retóricas melódicas. Por esse motivo, é imprescindivel uma busca constante de um estudo mais detalhado e descritivo sobre questões relacionadas ao uso de mecanismos retórico-musicais, adicionando maiores números de exemplos para análise. 
Enfim, nos oito exemplos aqui verificados, adicionados à observação desses elementos retóricos, tal qual a figura do Polyptoton, além da relação texto-musica e das funções harmônicas, confirmam a disposição dos recursos retóricos por Manuel Dias de Oliveira nessas peças, assim como da possibilidade da retórica como instrumento analítico para a compreensão dos processos composicionais nas músicas produzidas nesse período.

\section{Referências}

ALMEIDA, João Ferreira de. Biblia de Estudo de Genebra. São Paulo: Editora Cultura Cristã (Sociedade Bíblica do Brasil), 1999.

ARISTÓTELES. Retórica. Prefácio e Introdução Manuel Alexandre Júnior, Tradução e Notas Manuel Alexandre Júnior, Paulo Farmhouse Alberto e Abel do Nascimento Pena. Revisão de texto de Levi Condinho 2. ed. Lisboa, Centro de Filosofia da Universidade de Lisboa, Imprensa Nacional-Casa da Moeda, 2005.

BARTEL, Dietrich. Musica Poetica: musical-rhetorical figures in German Baroque Music. Lincoln: University of Nebraska Press, 1997.

BUELOW, George. Rhetoric and Music. In: SADIE, Stanley; TYRRELL, John (Eds.). The new grove dictionary of music and musicians. New York: Oxford University Press, 200 1. v. 21 , p. 260-275.

BURMEISTER, Joachim. Musical Poetics. Tradução, introdução e notas, Benito V. Rivera. New Haven and London: Yale University Press, 1993.

CASTAGNA, Paulo Augusto. (Org.). Missas: Restauração e Difusão de Partituras. (Missa de Oitavo Tom de Manuel Dias de Oliveira-Edição de Paulo Augusto Castagna). 1. ed. Belo Horizonte: Fundação Cultural e Educacional da Arquidiocese de Mariana, v. 2, 2001.

DOTTORI, Maurício. Ut Rhetorica Musica: análise do moteto $\bigcirc$ Vos Omnes a dois coros, de Manoel Dias de Oliveira. Revista Música, São Paulo, v. 3, n. 1, p. 53-69. 1992. 
CUIMARÃES, Elisa. Figuras de Retórica e Argumentação. In: MOSCA, Lineide do Lago Salvador. Retóricas de ontem e de hoje. 3. ed. São Paulo: Associação Editorial Humanitas, 2004. p. 1 45- 160.

LAUSBERG, Heinrich. Elementos de Retórica Literária. Tradução, prefácio e aditamentos de Raul Miguel Rosaldo Fernandes. 5. ed. Lisboa: Fundação Calouste Gulbernkian, 2004.

LÓPEZ CANO, Rubén. Música y retórica en el Barroco. México: Gráfica da Universidade Nacional Autônoma do México, 2000. 2 v.

OLIVEIRA, Manoel Dias de. Matinas e Vésperas de Sábado Santo. Ed. Maurício Dottori. São Paulo: EDUSP (Música Brasileira 2), 2000.

Moteto dos Passos. Partitura. Rest. Maurício Dottori. São Paulo. s/d.

Moteto dos Passos de Manuel Dias de Oliveira (Bajulans e $\bigcirc$ Vos Omnes). Partitura. Edição de Rafael Sales Arantes. São João do Del-Rey: IMSLP Contributor Page, 2017. Disponivel em: <https://imslp.org/ wiki/O_vos_omnes_para_Ver\%C3\%B4nica_No.4_(Oliveira\%2C_Manoel_ Dias_de) $>$. Acesso em: 17/5/2019.

RICCIARDI, Rubens Russomanno. Manuel Dias de Oliveira: um compositor brasileiro dos tempos coloniais - partituras e documentos. 142 f + anexos. Tese (Doutorado em Artes) - Pós-Graduação em Música, Escola de Comunicações e Artes, ECA, Universidade de São Paulo, USP, São Paulo, 2000.

Domine Jesu de Manuel Dias de Oliveira ( $\mathrm{s} / \mathrm{d})$. Edição de Rubens Russomanno Ricciardi. Partituras brasileiras: brazilian international songbook online-concert music - v. 6. Rio de Janeiro: Fundação Nacional de Artes (FUNARTE), 2017.

SOARES, Eliel Almeida. A utilização de elementos e figuras de retórica nos Ofertórios de André da Comes. 461 f. Dissertação (Mestrado em Musicologia). Programa de Pós-Graduação em Música, Escola de Comunicações e Artes (ECA), Universidade de São Paulo (USP), São Paulo, 2012. Disponivel em: <https://www.teses. usp.br/teses/disponiveis/27/27 157/tde-06032013-16/515/publico/ ElielAlmeidaSoares.pdf>. Acesso em 15/7/2019. 
Retórica: um novo objeto de estudo na música colonial brasileira. In: SIMPÓSIO BRASILEIRO DE PÓS-CRADUANDOS EM MÚSICA, 3., 2014, Rio de Janeiro. Anais... Rio de Janeiro: Unirio, 2014. p. 1-11. Disponivel em: <http://www.seer.unirio.br/index.php/simpom/article/ download/4668/4 167>. Acesso em: 23/5/2019.

- Emprego da Retórica na Música Colonial Brasileira. 533 f. Tese (Doutorado em Música) - Pós-Graduação em Música, Escola de Comunicações e Artes, ECA, Universidade de São Paulo, USP, São Paulo, 2017. Disponível em: <https://www.teses.usp. $\mathrm{br} / \mathrm{teses} /$ disponiveis/27/27 157/tde-07072017-141033/publico/ ELIELALMEIDASOARESVC.pdf>. Acesso em 18/7/2019.

A retórica em quatro compositores da música colonial brasileira: Manuel Dias de Oliveira, José Joaquim Emerico Lobo de Mesquita, André da Silva Comes e José Maurício Nunes Garcia. Per Musi, v. 39, n.2 p. 1-31. Ago.2019. <https://doi.org/10.35699/23176377.2019.14913>. Disponível em: <https://periodicos.ufmg.br/index. php/permusi/article/view/14913/12039>. Acesso em 20/8/2019.

\section{Sobre os autores}

Eliel Almeida Soares é graduado em Música (2008), Mestre (2012) e Doutor (2017) em Musicologia pelo Departamento e Programa de Pós-Graduação em Música da Escola de Comunicações e Artes da Universidade de São Paulo (ECA-USP). Desenvolveu com apoio financeiro da bolsa de doutorado da Fundação de Amparo à Pesquisa do Estado de São Paulo (FAPESP-Processo n²0 $13 / 23600-3$ ), pesquisas sobre as estruturas discursivas na música colonial brasileira. Também possui diversos trabalhos publicados sobre retórica musical. Atualmente faz parte do Núcleo de Pesquisa em Ciências da Performance em Música do Departamento de Música da Faculdade de Filosofia, Ciências e Letras de Ribeirão Preto da Universidade de São Paulo (NAP-CIPEM-DMFFCLRP-USP), onde desenvolve seu pós-doutoramento sob a supervisão do Prof. Dr. Rubens Russomanno Ricciardi. 
Rubens Russomanno Ricciardi é compositor, maestro, pianista e musicólogo. Graduado em Música (1985), Mestre em Musicologia (1996), Doutor em Musicologia (2000) pelo Departamento de Música e Programa de Pós-Graduação em Música da Escola de Comunicações e Artes da Universidade de São Paulo (ECA-USP) e Livre-Docente em Teoria e Análise (2003) pela mesma instituição. Fundador, professor titular e decano do Departamento de Música da Faculdade de Filosofia, Ciências e Letras de Ribeirão Preto da Universidade de São Paulo (DM-FFCLRP-USP), onde fundou e dirige a USP-Filarmônica, o Centro de Memória das Artes, o Núcleo de Pesquisa em Ciências da Performance em Música (NAP-CIPEM). Professor responsável pelo Festival Música Nova "Gilberto Mendes" e pelo projeto USP-Música.

Recebido em 04/09/2019

Aprovado em 15/01/2020 